\title{
CAUSES OF SUDDEN CARDIAC DEATH- AN AUTOPSY STUDY
}

\author{
Rajeev V.M1', Santhosh Joy², Ravi Kumar $K^{3}$
}

${ }^{1}$ Associate Professor, Department of Forensic Medicine, Government Medical College, Kottayam. ${ }^{2}$ Assistant Professor, Department of Forensic Medicine, Government Medical College, Kottayam. 3Junior Resident, Department of Forensic Medicine, Government Medical College, Kottayam.

\begin{abstract}
BACKGROUND by the doctor, should be subjected to medico-legal autopsy.

Objectives-

1. To find out the age and sex distribution of victims who died of 'sudden cardiac death'.

2. To find out the aetiological factors associated 'with sudden cardiac death'.
\end{abstract}

ABSTRACT

Sudden death is defined in many different ways by different authorities. Some believe that the term should be restricted to those cases wherein the time of onset of symptoms to 'collapse and death', is instantaneous or within minutes. In forensic parlours, "sudden death" is defined in a little different way as an 'apparently normal person, who is not known to be suffering from any illness, suddenly falls ill and dies within 24 hours of onset of the disease symptoms. In short 'sudden death' is restricted to natural causes only. Sudden unexpected natural death cases in adults are steadily increasing world over and is an issue of great concern for medical professionals. Sudden death especially of a young and apparently healthy adult is not only shocking but also has profound impact on the psyche of the society. Most of the sudden deaths occur outside the hospitals and in the emergency rooms, reflecting their unexpected character. As per the Indian law, all cases of sudden unexpected deaths or deaths in which the cause of death was not diagnosed or ascertained

\section{MATERIALS AND METHODS}

Study design- Retrospective case series study.

Sample size- 230 cases of sudden natural death brought for autopsy.

Source population- All cases of sudden natural death brought for autopsy to the Department of Forensic Medicine Government Medical College, Kottayam during the year 2016.

Inclusion Criteria- All autopsies in which death was due to sudden natural death were included in the study.

Exclusion criteria-

1. All unidentified bodies.

2. All decomposed bodies.

Data collection- Baseline data like age, sex, history of any previous illness, and a brief history of the case were collected from the requisition provided by the investigating officer. Details of the post-mortem findings were collected from the post-mortem certificate.

Analysis- Data collected was entered in MS-Excel and analysed using SPSS version 15.

\section{RESULTS}

Among the 230 cases of sudden natural death, 155 (67.4\%) were due to occlusive coronary artery disease, a natural disease of the heart. The next most common cause was Pneumonia, 19 (8.3\%) cases; followed by Cerebrovascular disease, 17 (7.4\%) cases; Pulmonary tuberculosis, 9 cases (3.9\%); Chronic obstructive pulmonary disease, 6 (2.6\%) cases; Ruptured oesophageal varices, 5 (2.2\%) cases; and septicaemia 4 (1.7\%) cases.

\section{CONCLUSION}

Occlusive coronary artery disease is the most common cause of sudden natural death (67.4\%). The age group most commonly involved in sudden cardiac death was 51-60 years (27.7\%) followed by 61-70 years (21.3\%) and 41-50 years (19.4\%). 41 to 70 years age group is the most vulnerable group (68.4\%) to be affected by sudden cardiac death. Among those involved in sudden cardiac death, 83.8\% were males. Atherosclerosis is the dominant cause of cardiovascular disease including myocardial infarction. The most common coronary artery affected by atherosclerosis was the anterior descending branch of the left coronary artery (93.5\%). The right coronary artery was affected in $65.8 \%$. Coronary thrombosis is the reason for most cases of sudden cardiac death.

\section{KEYWORDS}

Sudden Death, Coronary Thrombosis, Autopsy.

HOW TO CITE THIS ARTICLE: Rajeev VM, Joy S, Kumar RK. Causes of sudden cardiac death- An autopsy study. J. Evolution Med. Dent. Sci. 2017;6(95):6993-6997, DOI: 10.14260/jemds/2017/1518

'Financial or Other Competing Interest': None.

Submission 04-11-2017, Peer Review 29-11-2017,

Acceptance 04-12-2017, Published 23-12-2017.

Corresponding Author:

Dr. Rajeev $V . M$

Associate Professor, Department of Forensic Medicine,

Government Medical College, Kottayam.

E-mail: drrajeevvm3056@gmail.com

DOI: $10.14260 /$ jemds $/ 2017 / 1518$

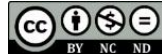

\section{BACKGROUND}

Majority of cases dealt with by forensic surgeons entail violence against human body, whether accidental, suicidal, or homicidal, there is still another large group of deaths which has to be investigated by them, a condition termed as, "sudden death due to natural causes". Sudden death may occur due to emotional excitement, mental tension, or arduous physical exercise in the presence of other people, or while alone or sleeping in the bed, when suspicion may arise as to the manner 
and cause of death. The deceased would have been apparently normal, but would have had some pre-existing disease like coronary or cerebrovascular disease and the precipitating factor would be inconsequential, like a fall or a blow which is 'simple' in nature. In other cases, there may be a wellrecognised clinical history and hospital record, which allows the forensic surgeon for determining the cause of death free from any serious doubt. But in practice many of them present with little or no history and that are what comprise one of the most perplexing challenges even an accomplished forensic surgeon has to deal with.

Sudden death is defined in many different ways by different authorities. Some believe that the term should be restricted to those cases wherein the time of onset of symptoms to 'collapse and death', is instantaneous or within minutes. In forensic parlours, "sudden death" is defined in a little different way as an 'apparently normal person, who is not known to be suffering from any illness, suddenly falls ill and dies within 24 hours of onset of the disease symptoms. In short 'sudden death' is restricted to natural causes only. Sudden unexpected natural death cases in adults are steadily increasing world over and is an issue of great concern for medical professionals. ${ }^{1}$ Sudden death especially of a young and apparently healthy adult is not only shocking but also has profound impact on the psyche of the society. ${ }^{2}$ Most of the sudden deaths occur outside the hospitals and in the emergency rooms, reflecting their unexpected character. ${ }^{3}$ As per the Indian law, all cases of sudden unexpected deaths or deaths in which the cause of death was not diagnosed or ascertained by the doctor, should be subjected to medico-legal autopsy. 4

Sudden natural death accounts for approximately $10 \%$ of all deaths. ${ }^{5}$ Sudden cardiac death is commonly defined as an unexpected natural death due to cardiac causes. ${ }^{6}$ Diseases of cardiovascular system account for $45 \%$ to $50 \%$ of all sudden deaths. ${ }^{7}$ At least $80 \%$ of patients who experience sudden cardiac death have coronary artery disease as the underlying anatomic substrate due to atherosclerotic changes of the coronary arteries. Left ventricular failure and cardiogenic shock is the most feared complication of acute myocardial infarction. 6 The number of sudden deaths is increasing to a great extent these days due to many risk factors like life-style diseases, fast food culture, addictions like smoking and alcoholism, sedentary life styles and occupation, etc. ${ }^{8}$ It is estimated that about $40-50 \%$ of all cardiovascular deaths are sudden cardiac deaths. As per WHO statistics, mortality due to cardiac causes has overtaken mortality due to all cancers put together. ${ }^{9}$ Approximately 4280 out of every one lakh people die every year from sudden cardiac death in India alone. ${ }^{10}$ Prevention of cardiovascular disease by increasing awareness of risk factors such as lack of exercise, inappropriate diet and smoking has reduced cardiovascular mortality in developed countries over the past few decades. Therefore, there is a need to develop complementary strategies for management of sudden cardiac death in our country. Atherosclerotic coronary artery disease is the underlying cause of approximately 75 to 90 percent of sudden cardiac deaths. ${ }^{11,12}$

\section{Objectives}

1. To find out the age and sex distribution of victims who died of 'sudden cardiac death'.

2. To find out the aetiological factors associated 'with sudden cardiac death'.

\section{MATERIALS AND METHODS}

\section{Study Design}

Retrospective case series study.

\section{Sample Size}

230 cases of sudden natural death brought for autopsy.

\section{Source population}

All cases of sudden natural death brought for autopsy to the Department of Forensic Medicine Government Medical College, Kottayam during the year 2016.

\section{Inclusion Criteria}

All autopsies in which death was due to sudden natural death were included in the study.

\section{Exclusion Criteria}

1. All unidentified bodies.

2. All decomposed bodies.

\section{Data Collection}

Baseline data like age, sex, history of any previous illness, and a brief history of the case were collected from the requisition provided by the investigating officer. Details of the postmortem findings were collected from the post-mortem certificate

\section{Analysis}

Data collected was entered in MS-Excel and analysed using SPSS version 15 .

\section{RESULTS}

During the year 2016, 230 cases of sudden natural death were brought for autopsy in the Department of Forensic Medicine, Govt. Medical College, Kottayam.

\section{Types of diseases causing sudden natural death:}

There were 230 cases of sudden natural death brought for autopsy to the Department of Forensic Medicine Govt. Medical College, Kottayam in the year 2016. Among the 230 cases of sudden natural death, $155(67.4 \%)$ were due to Occlusive coronary artery disease, a Natural disease of the heart.

The next most common cause was Pneumonia, 19 (8.3\%) cases; followed by Cerebrovascular disease, 17 (7.4\%) cases; Pulmonary tuberculosis, 9 cases (3.9\%); Chronic obstructive pulmonary disease, 6 (2.6\%) cases; Ruptured oesophageal varices, 5 (2.2\%) cases; and septicaemia 4 (1.7\%) cases.

There were 2 cases each of death due to myocarditis, Brain abscess, Pyelonephritis, Aortic dissection and Pancreatitis.

There was one case each of Liver abscess, Ectopic pregnancy, Anomalous origin of left coronary artery, hypertrophic cardiomyopathy and Dengue fever. 


\begin{tabular}{|c|c|c|c|}
\hline & Type of Disease & No. of Cases & $\%$ \\
\hline 1 & Coronary artery disease & 155 & 67.4 \\
\hline 2 & Pneumonia & 19 & 8.3 \\
\hline 3 & Cerebrovascular disease & 17 & 7.4 \\
\hline 4 & Pulmonary Tuberculosis & 9 & 3.9 \\
\hline 5 & COPD & 6 & 2.6 \\
\hline 6 & Rupture of oesophageal varices & 5 & 2.2 \\
\hline 7 & Septicaemia & 4 & 1.7 \\
\hline 8 & Myocarditis & 2 & 0.9 \\
\hline 9 & Brain abscess & 2 & 0.9 \\
\hline 10 & Pyelonephritis & 2 & 0.9 \\
\hline 11 & Aortic dissection & 2 & 0.9 \\
\hline 12 & Pancreatitis & 2 & 0.9 \\
\hline 13 & Liver abscess & 1 & 0.4 \\
\hline 14 & Ectopic pregnancy & 1 & 0.4 \\
\hline 15 & $\begin{array}{c}\text { Anomalous origin left coronary } \\
\text { artery }\end{array}$ & 1 & 0.4 \\
\hline 16 & Hypertrophic cardiomyopathy & 1 & 0.4 \\
\hline 17 & Dengue fever & 1 & 0.4 \\
\hline & Total & 230 & 100 \\
\hline
\end{tabular}

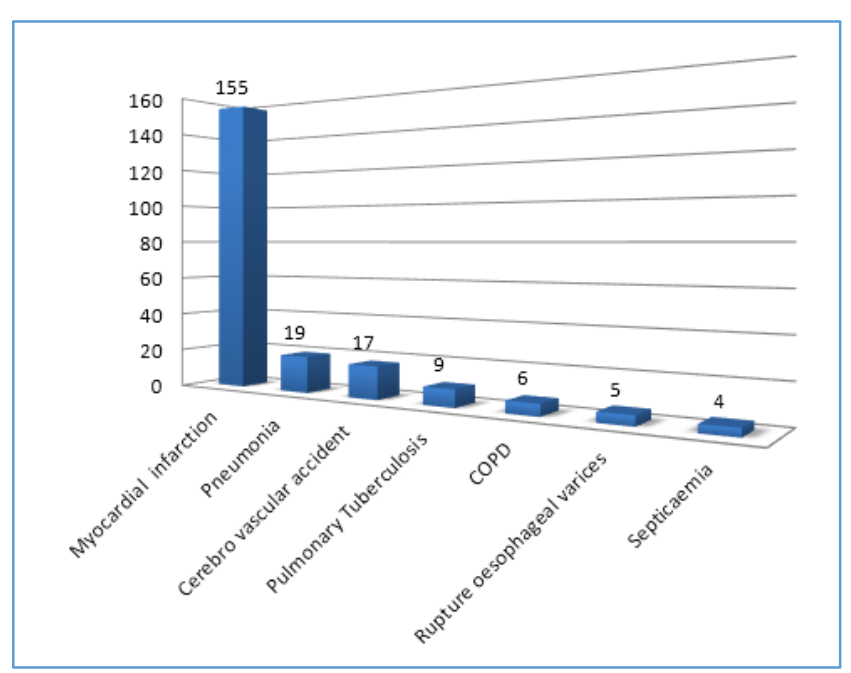

Figure 1. Causes of Sudden Natural Death

Age Distribution of Occlusive Coronary Artery Disease

The vast majority of cases were in the age group of 51-60, 43 cases (27.7\%); followed by 61-70 age group, 33 cases (21.3\%); and 30 cases $(19.4 \%)$ were in the $41-50$ age group. This was followed by 16 cases (10.3\%) and 15 cases (9.7\%) in the 3140 and 71-80 age groups respectively. There were only 9 cases (5.8\%) and 8 cases (5.2\%) in the 21-30 and $81-90$ age group respectively. There was only one case in the 10-20 age group.

\begin{tabular}{|c|c|c|}
\hline Age Group & Incidence & Percentage \\
\hline $10-20$ & 1 & 0.6 \\
\hline $21-30$ & 9 & 5.8 \\
\hline $31-40$ & 16 & 10.3 \\
\hline $41-50$ & 30 & 19.4 \\
\hline $51-60$ & 43 & 27.7 \\
\hline $61-70$ & 33 & 21.3 \\
\hline $71-80$ & 15 & 9.7 \\
\hline $81-90$ & 8 & 5.2 \\
\hline Total & 155 & 100 \\
\hline \multicolumn{3}{|c|}{ Table 2. Age Distribution of Sudden Cardiac } \\
Death (N=155) \\
\hline
\end{tabular}

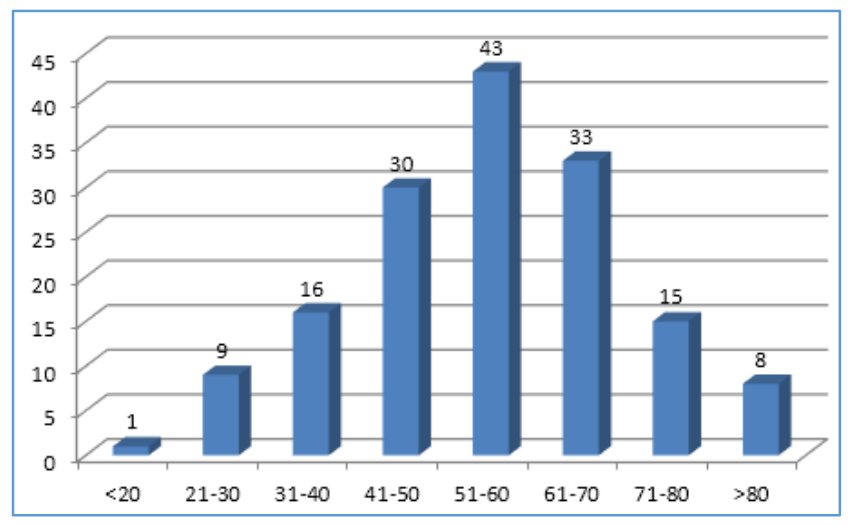

Figure 2. Age Distribution of Sudden Cardiac Death

Sex distribution of sudden cardiac death

Out of 155 cases of death due to sudden cardiac death, there were 130 males (83.8\%) and $25(16.2 \%)$ females.

\begin{tabular}{|c|c|}
\hline Sex & Incidence \\
\hline Male & 130 \\
\hline Female & 25 \\
\hline Total & 155 \\
\hline Table 3 Sex Distribution Sudden Cardiac Death (N=155)
\end{tabular}

Table 3. Sex Distribution Sudden Cardiac Death ( $=155)$

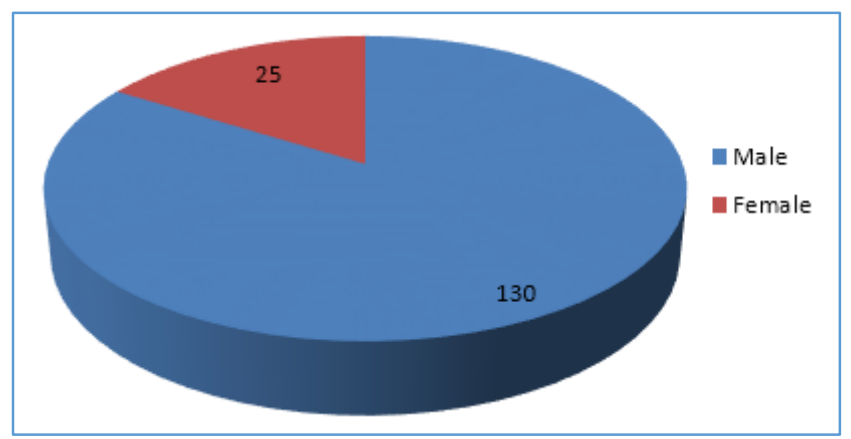

Figure 3. Sex Distribution of Sudden Cardiac Death

Distribution of Atherosclerotic Changes in Aorta and Coronaries

Among the 155 cases of death due to occlusive coronary artery disease, $116(74.8 \%)$ cases showed atheromatous changes in the aorta. In 39 cases (25.2\%) no atheromatous changes were noted.

Among the 155 cases of cardiac death, 145 (93.5\%) cases showed atheromatous narrowing of the anterior descending branch of the left coronary artery. In 102 (65.8\%) cases, the right coronary artery showed atheromatous changes. Only 30 cases (19.4\%) showed atheromatous changes in the circumflex artery.

\begin{tabular}{|c|c|c|}
\hline Site & Distribution & Percentage \\
\hline Aorta & 116 & 74.8 \\
\hline LAD & 145 & 93.5 \\
\hline RCA & 102 & 65.8 \\
\hline Cx & 30 & 19.4 \\
\hline Total & 155 & 100 \\
\hline
\end{tabular}

Table 4. Distribution of Atherosclerotic Changes in Aorta and Coronaries $(N=155)$ 


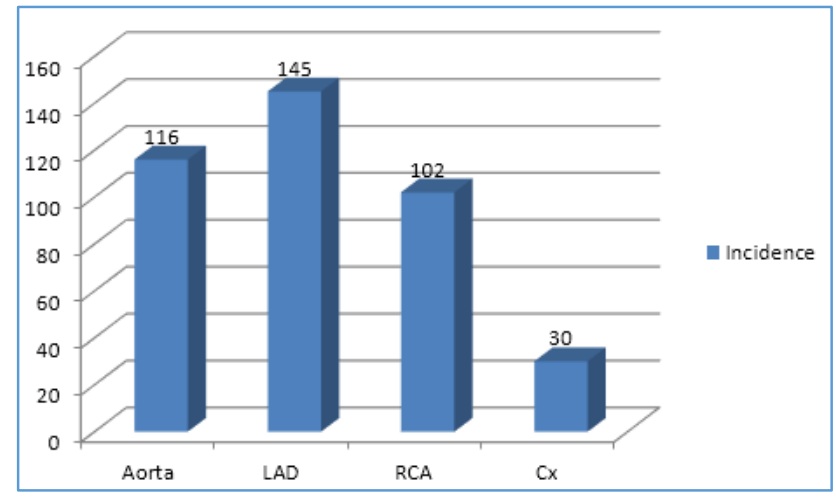

Figure 4. Distribution of Atherosclerotic Changes in Aorta and Coronaries

\section{Distribution of Thrombus in the Coronary Arteries}

Out of 155 cases of sudden cardiac death, thrombus was detected in the anterior descending branch of left coronary artery in 37 cases (23.9\%). In 16 cases (10.3\%) thrombus was detected in the right coronary artery and in only 6 cases (3.9\%) thrombus was noted in the circumflex branch of the left coronary artery.

\begin{tabular}{|c|c|c|}
\hline Site & Thrombus & Percentage \\
\hline $\begin{array}{l}\text { Anterior descending branch of } \\
\text { left coronary(LAD) }\end{array}$ & 37 & 23.9 \\
\hline Right coronary(RCA) & 16 & 10.3 \\
\hline Circumflex (Cx) & 6 & 3.9 \\
\hline \multicolumn{3}{|c|}{$\begin{array}{l}\text { Table 5. Distribution of Thrombus in the Coronary } \\
\text { Arteries }(N=155)\end{array}$} \\
\hline
\end{tabular}

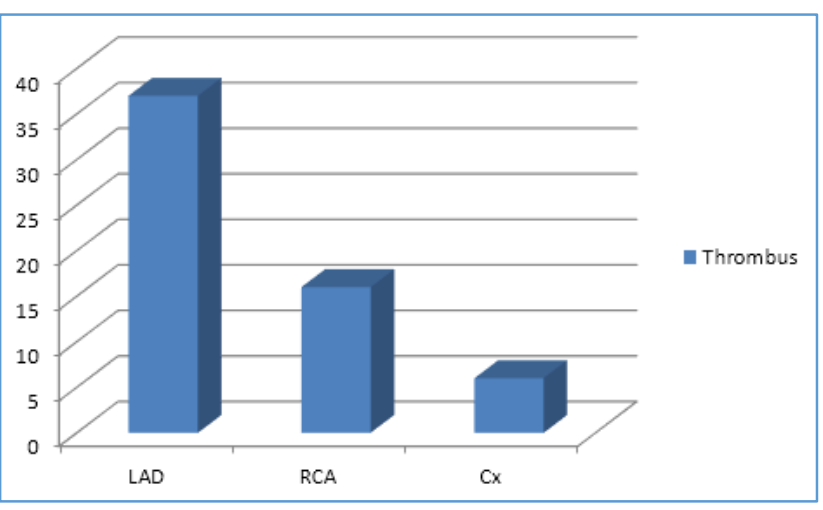

Figure 5. Distribution of Thrombus in Coronary Arteries

Distribution of Myocardial Fibrosis

Among the 155 cases of sudden cardiac death, 56 cases (36.1\%) showed fibrosis or scarring of the left ventricle. Only 9 cases $(5.8 \%)$ showed scarring of the right ventricle.

\begin{tabular}{|c|c|c|}
\hline Site & Fibrosis & Percentage \\
\hline Left Ventricle & 56 & 36.1 \\
\hline Right Ventricle & 9 & 5.8 \\
\hline \multicolumn{2}{|c|}{ Table 6. Distribution of Myocardial Fibrosis $(\mathbf{N = 1 5 5 )}$} \\
\hline
\end{tabular}

\section{Hypertrophy of Heart}

Out of 155 cases of cardiac death, 32 cases (20.6\%) showed hypertrophy of the left ventricle. Right ventricle was thickened in 8 cases (5.2\%).

\begin{tabular}{|c|c|c|}
\hline Site & Hypertrophy & Percentage \\
\hline Left ventricle & 32 & 20.6 \\
\hline Right ventricle & 8 & 5.2 \\
\hline \multicolumn{2}{|c|}{ Table 7. Hypertrophy of Heart $(\mathbf{N = 1 5 5 )}$} \\
\hline
\end{tabular}

\section{Miscellaneous Findings}

Hypoplasia of the anterior descending branch of the left coronary artery was noted in 4 cases $(2.6 \%)$. There were 6 cases $(3.9 \%)$ of Hypoplasia of the right coronary artery. There were 2 cases $(1.3 \%)$ of sudden death due to cardiac tamponade following rupture of heart as a complication of myocardial infarction.

\begin{tabular}{|c|c|c|}
\hline Site & No. of Cases & Percentage \\
\hline Hypoplasia LAD & 4 & 2.6 \\
\hline Hypoplasia RCA & 6 & 3.9 \\
\hline Cardiac tamponade & 2 & 1.3 \\
\hline \multicolumn{2}{|r|}{ Table 8. Miscellaneous Findings $(\mathbf{N = 1 5 5})$}
\end{tabular}

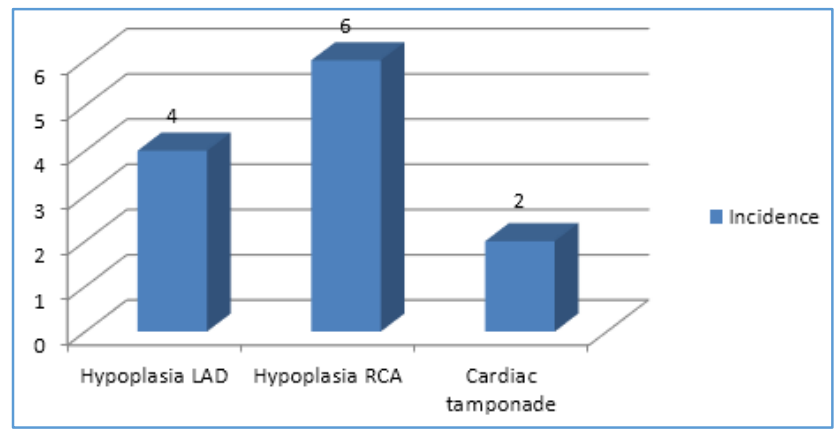

Figure 6. Miscellaneous Findings

\section{DISCUSSION}

A retrospective case series study was conducted in the Department of Forensic Medicine on cases of sudden natural death brought for post-mortem examination during the year 2016. There were 230 cases of sudden natural death out of which the vast majority of cases, 155 (67.4\%), were death due to occlusive coronary artery disease. This is in accordance with data available in Taylor's Principle and Practice of Medical jurisprudence, in which the incidence of death due to occlusive coronary artery disease was 58\%.13 Sudden cardiac death accounts for $\approx 50 \%$ of the estimated 500000 cardiovascular deaths that occur annually in the United States, and a vast majority are the result of coronary artery disease. ${ }^{14}$

The age group most commonly involved was 51-60 years 43 cases $(27.7 \%)$, followed by $61-70$ years, 33 cases $(21.3 \%)$ and those of $41-50$ years, 30 cases (19.4\%). Thus, it is clear that if we took the age group 41-70 years there are 106 cases $(68.4 \%)$ out of the total of 155 cases of death due to occlusive coronary artery disease. Thus, the age between 40 to 70 years is the most vulnerable group. Among the 155 cases of sudden death due to occlusive coronary artery disease, 130 cases $(83.8 \%)$ were males and only 25 cases were females. The risk was 2 to 3 -fold higher in men than in women, and increased with age. 15

Atherosclerosis is the dominant cause of cardiovascular disease including myocardial infarction, heart failure, and stroke. Atherosclerosis is mainly located in the intima of many middle sized and large arteries, especially where the vessels divide. In the present study, among the 155 cases of occlusive coronary artery disease, the most commonly involved artery 
was the anterior descending branch of the left coronary artery, 145 cases $(93.5 \%)$. The right coronary artery was affected in 102 cases $(65.8 \%)$. The circumflex branch of the left coronary artery was the least involved, 30 cases (19.4\%). Because coronary artery disease is an important manifestation of the disease, epidemiologic data related to atherosclerosis mortality typically reflect deaths caused by ischaemic heart disease (IHD). ${ }^{16}$

Coronary thrombosis is the reason for most cases of sudden cardiac death. In the present study, the most commonly affected vessel was the anterior descending branch of the left coronary artery, 37 cases (23.9\%); followed by proximal part of right coronary artery, 16 cases $(10.3 \%)$; and lastly circumflex branch of the left coronary artery, 6 cases (3.9\%). Impaired endothelium may abnormally reduce vascular perfusion, produce factors that decrease plaque stability, and augment the thrombotic response to plaque rupture. ${ }^{17}$ Coronary thrombosis may occur on the ulcerative atheromatous lesions usually or even in virtually normal arteries especially in middle aged women where thrombosed aneurysms may be seen. Such aneurysms occur usually in right coronary artery. 18

\section{CONCLUSION}

1. Occlusive coronary artery disease is the most common cause of sudden natural death (67.4\%).

2. The age group most commonly involved in sudden cardiac death was 51-60 years (27.7\%), followed by 61-70 years, (21.3\%), and $41-50$ years (19.4\%).

3. 41 to 70 years age group is the most vulnerable group (68.4\%) to be affected by sudden cardiac death.

4. Among those involved in sudden cardiac death, $83.8 \%$ were males.

5. Atherosclerosis is the dominant cause of cardiovascular disease including myocardial infarction.

6. The most common coronary artery affected by atherosclerosis was the anterior descending branch of the left coronary artery (93.5\%). The right coronary artery was affected in $65.8 \%$.

7. Coronary thrombosis is the reason for most cases of sudden cardiac death.

\section{REFERENCES}

[1] Chaturvedi M, Satoskar M, Khare MS, et al. Sudden, unexpected and natural death in young adults of age between 18 and 35 years: a clinicopathological study. Indian J Pathol Microbiol 2011;54(1):47-50.

[2] Suarez-Mier MP, Aguilera B. Causes of sudden death during sports activities in Spain. Rev Esp Cardiol 2002;55(4):347-58.

[3] Morentin B, Aguilera B, Garamendi PM, et al. Sudden unexpected non-violent death between 1 and 19 years in north Spain. Arch Dis Child 2000;82(6):456-61.
[4] Mittal G, Menon A, Krishnan M, et al. Analysis of sudden deaths in a coastal region of South India. Indian Council of Medical Research Short-term Studentship 2010 programme vide sanction letter no. 2010-00496(ICMR, STS2010).26.08.2013.http://dx.doi.org/10.7713/ijms. 2013.0041/copied on $12^{\text {th }}$ November 2014 at 20.36 hours.

[5] De la Grandmaison GL. Is there progress in the autopsy diagnosis of sudden unexpected death in adults? Forensic Science International 2006;156(2-3):138-44.

[6] Ahmad M, Afzal S, Malik IA, et al. An autopsy study of sudden cardiac death. Journal of Pakistan Medical Association 2005;55(4):149-52.

[7] Reddy NKS. The essentials of forensic medicine and toxicology. Chapter on death and its cause. 29th edn. 2010:136-7.

[8] WHO library cataloguing-in-publication data. World Health Organization. Preventing chronic diseases: a vital investment: WHO global report, 2005.

[9] Announcement / Corporate Jul 20, 2009, 16:02 IST http://www.businessstandard.com/india/news/sudd en-cardiac-arrest-claiming-about-4280-livesevery-1lakhpopulation-annually/364594/copied on $10^{\text {th }}$ november 2014 at 19.20 hours

[10] Mehra R. Global public health problem of sudden cardiac death. J Electrocardiol 2007;40(6 Suppl):S11822.

[11] Dowling G. Sudden natural death. Dolinak D, Matshes EW, Lew EO. eds. Forensic pathology: principles and practice. Amsterdam: Elsevier Academic Press 2005:110-12.

[12] El-Sherif N, Khan A, Savarese J, et al. Pathophysiology, risk stratification and management of sudden cardiac death in coronary artery disease. Cardiology Journal 2010;17(1):4-1.

[13] Craig-Hunter C. Deaths due to sudden or unexpected natural causes. In: Mart AK. edr. Taylor's Principle and practice of medical jurisprudence. Edinburgh: Churchill Livingstone 1984:111-27.

[14] Myerburg RJ, Castellanos A. Cardiac arrest and sudden cardiac death. In: Braunwald E. edr. Heart disease: a textbook of cardiovascular medicine. Philadelphia, Pa: WB Saunders 1992:756-89.

[15] Straus SM, Bleumink GS, Dieleman JP, et al. The incidence of sudden cardiac death in the general population. J Clin Epidemiol 2004;57(1):98-102. https://doi.org/10.1016/S0895-4356(03)00210-5

[16] Kumar V, Abbas AK, Fausto N. Robbins and Cotran pathologic basis of disease. $8^{\text {th }}$ edn. Saunders 2010: p. 343, 353-7, 400-9, 417-18.

[17] Loscalzo J. Nitric oxide insufficiency, platelet activation and arterial thrombosis. Circulation Research 2001;88:756-62.

[18] Gradwohl RBH, Camps FE, Robinson AE, et al. Gradwohl's legal medicine. $3^{\text {rd }}$ edn. 1976:222-8. 